\title{
Suppression of histamine-induced increase of endothelial permeability via nitric oxide production by Bixa orellana leaves extract.
}

\begin{abstract}
Previously reported pharmacological activity of Bixa orellana L. (Bixaceae) includes its ability to neutralize edema-forming effects of Bothrops asper venom (Nunez V., et al, 2004). Study on the mechanism of its anti-edema activity is thus far lacking. The purpose of this study was to examine the effects of aqueous extract of B. orellana (AEBO) leaves on endothelial permeability and the permeability-regulator molecule, nitric oxide (NO), during inflammatory stimulation by histamine. This study demonstrated that AEBO $(0.1 \mathrm{mg} / \mathrm{ml}$ $0.4 \mathrm{mg} / \mathrm{ml}$ ) significantly (p\&lt;0.05) suppressed histamine-induced increased endothelial permeability in human umbilical veins endothelial cells (HUVECs), where maximal inhibition was $90.2 \%$ at concentration and time point of $0.4 \mathrm{mg} / \mathrm{ml}$ and $15 \mathrm{~min}$, respectively. Histamine-mediated NO formation in HUVECs was significantly reduced by all concentration of AEBO in a dose-dependent manner. $0.4 \mathrm{mg} / \mathrm{ml}$ showed maximal inhibition where it reduced NO level from $12.51 \pm 0.07 \mu \mathrm{M}$ to $11.3 \pm 0.07 \mu \mathrm{M}$ (65.4\% inhibition). On the other hand, 0.1 and $0.2 \mathrm{mg} / \mathrm{ml}$ of AEBO suppressed NO production at $21.70 \%$ and $34.50 \%$, respectively. To verify that AEBO will produce similar effects to exogenous source of NO as to endogenous NO, NO donor, sodium nitroprusside (SNP) was used. AEBO showed significant effects in scavenging NO radicals released by SNP where maximal inhibition was $51.2 \%$ at $0.4 \mathrm{mg} / \mathrm{ml}$. These results indicate that AEBO suppressed increased endothelial permeability by re-establishing normal NO production in HUVECs. This study justifies the use of Bixa orellana in traditional medicine by showing its potential in regulating endothelial cell barrier function.
\end{abstract}

Keyword: Bixa orellana; Leaves extract; Histamine; Nitric oxide. 